\title{
Numerical Analysis of Polymer Foam Composite Material (PFCM) Reinforced by Palm Empty Bunch Fiber (PEBF) at Fracture Point Due to High Strain Impact Load
}

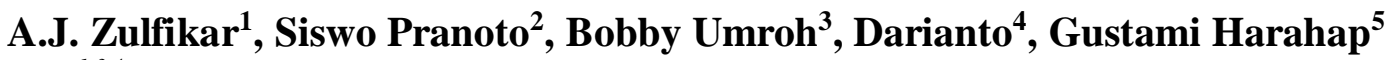 \\ ${ }^{1,3,4}$ Mechanical Engineering Study Program, Universitas Medan Area, Medan, Indonesia \\ ${ }^{5}$ Agribusiness Study Program, Universitas Medan Area \\ ${ }^{2}$ Mechanical Engineering Study Program, Sekolah Tinggi Teknologi Pekanbaru, Riau \\ zulfikar@staff.uma.ac.id
}

\begin{abstract}
In general, polymer composite materials are molded in solid form and avoid the occurrence of gas bubbles trapped in the matrix. The resulting material becomes rigid and does not have a good ability to absorb the load given. At this time, innovations in the field of composite materials have been carried out and produced polymer composite materials with foam-shaped structures that are able to reduce the load given. In this study, a composite foam material reinforced with PEBF fiber was tested with an impact dynamic load and the test results were numerically analyzed by the finite element method. The purpose of this study is to obtain the stress distribution at the fracture point due to the impact of dynamic loads at high strain rates with the finite element analysis method. Impact dynamic test using the Air Gun Compressor (AGC) test with an impact pressure of $0.2-0.8 \mathrm{MPa}$. Strain wave propagation in the test specimen was recorded using two strain gauges. Numerical analysis is carried out with the help of Msc. Nastran software. Experimentally, a failure in the specimen occurred at an impact pressure of $0.4 \mathrm{MPa}$ and an impact distance (ID) of $500 \mathrm{~mm}$. Strain wave propagation time in the specimen averaged $37.5 \mathrm{~ms}$, at which time the tensile and compressive stresses intersected at a distance of about 120 to $155 \mathrm{~mm}$ from the starting point of loading. The magnitude of the stress distribution in the range of the fracture zone is between 800 to $900 \mathrm{MPa}$.
\end{abstract}

Keywords: PFCM; PEBF; numerical analysis; impact load

\section{Introduction}

Composite material is material derived from several materials embedded in the binding media called a matrix and produces new materials with properties that are still influenced by the constituent materials (Elanchezhian et al., 2018). In general, this material is composed of two main components, namely reinforcement or known as fiber and one is a matrix. Reinforcement material is a component that becomes the strength of these materials which can consist of non-metallic materials such as glass or from metal materials such as aluminum. The matrix material is a protective fiber, so the load does not directly affect the fiber. Currently, composite materials are chosen as alternative materials because they have properties such as: light weight, easy to form, cheaper, and corrosion resistant (Wu et al., 2018).

Environmental damage due to the use of chemicals has become a broad issue in every environmental preservation effort. Toxic chemicals do not break down naturally in nature and some of their compounds can cause the death of living things due to chemical bonds they contain (Sarpong-kumankomah, Gibson and Gailer, 2018). One solution to this problem is to use natural ingredients that are environmentally friendly and have abundant resources. Preferably sourced natural materials from agricultural waste such as rice husks, banana stems, grass, etc., or from plantation wastes such as empty fruit palms, rubber tree wood, bagasse, 
Budapest International Research in Exact Sciences (BirEx) Journal

Volume 2, No 1, January 2020, Page: 86-95

e-ISSN: 2655-7827 (Online), p-ISSN: 2655-7835(Print)

www.bircu-journal.com/index.php/birex

emails: birex.journal@gmail.com

birex.journal.qa@gmail.com

etc. Specifically for this research, the waste that is utilized is palm oil mill waste, namely empty fruit bunches which are processed into palm empty bunch fiber (PEBF).

In Southeast Asia, especially Indonesia, the area of oil palm plantations is the largest (Johan et al., 2018). This factory waste is in the form of PEBF and has good potential if it can be used as raw material to build a type of composite material. Azlina et al (Azlina et al., 2019) have investigated the use of PEBF as a reinforcing material for phenolic hybrid composite materials. Based on these results, the highest tensile stress and modulus obtained in the composition 7PEFB: 3SCB with a value of 5.56 MPa and 661 MPa. Zulfikar et al (Zulfikar, Umroh and Siahaan, 2019) have examined the properties of this material due to high strain rate impact loads. The results obtained are the magnitude of the impact stress data distribution in the test of 15 samples ranging from $12-17 \mathrm{MPa}$ with an average value of $13.8 \mathrm{MPa}$.

The phenomenon of the impact load propagating on an elastic medium intensively was investigated by Kolsky in 1949 (Chen and Song, 2011). Strain wave propagation occurs due to particle interactions that occur in the elastic medium. The denser the arrangement of the particles, the faster the propagation speed will be. The velocity is calculated using equation (1), where $\mathrm{E}$ is the modulus of elasticity of the material and $\rho$ is the density of the material.

$$
\mathrm{C}=\sqrt{E / \rho}
$$

Incident stress is the initial stress that enters the specimen from the input bar (Cavalcanti and Tavares, 2019). This stress is obtained based on test results and it is seen from the strain propagation wave captured by strain gage (Fig. 1) (Chen and Song, 2011). If this stress can be obtained, the amount of impact load Fi entering the specimen surface can be calculated using equation (2), where $\sigma_{i}$ is incident stress and $A_{1}$ is the cross-sectional area of the test specimen.

$$
F_{i}=\sigma_{i} \cdot A_{1}
$$

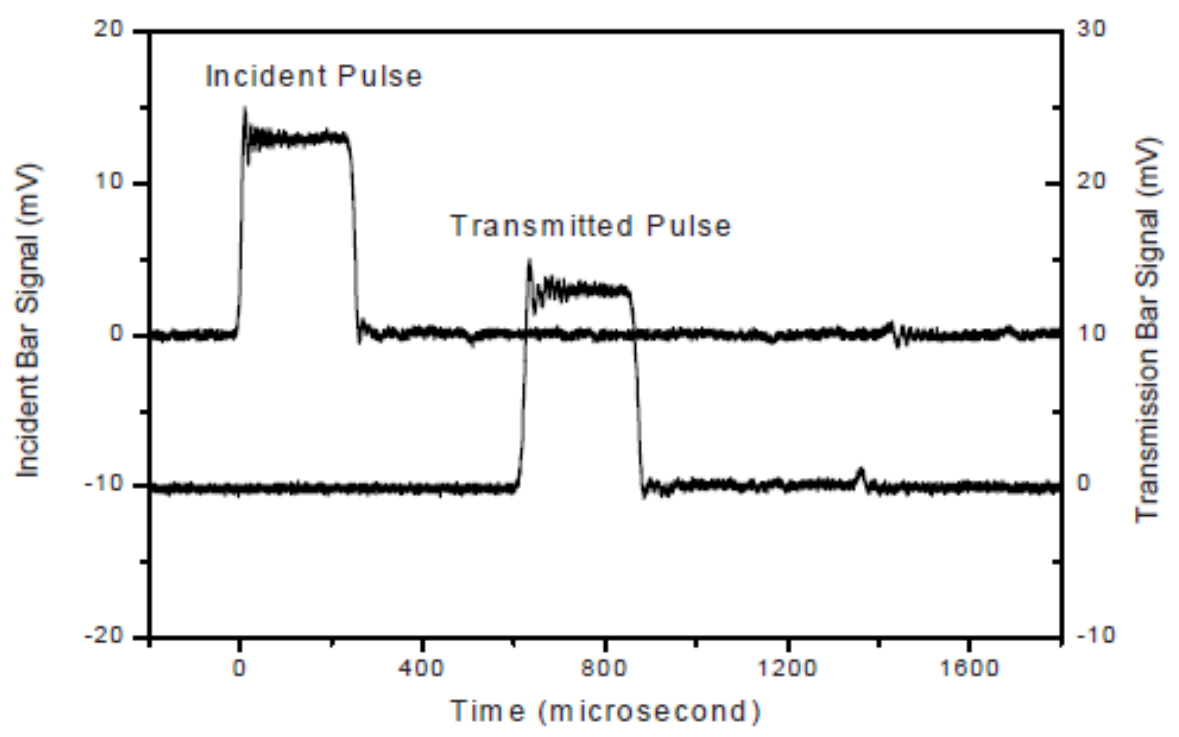

Figure 1. Stress waves in bars

Experimental material testing cannot accurately explain the distribution of stress strain wave propagation that occurs in specimens. In this type of testing, many strain gage sensors will be needed to get the data. As a result, there will be many sensors that must be attached to 
Budapest International Research in Exact Sciences (BirEx) Journal

Volume 2, No 1, January 2020, Page: 86-95

e-ISSN: 2655-7827 (Online), p-ISSN: 2655-7835(Print)

www.bircu-journal.com/index.php/birex

emails: birex.journal@gmail.com

birex.journal.qa@gmail.com

the specimen and sometimes even cause data complications when run. The solution to this problem is to use the help of Finite Element Method (FEM), where the specimen is divided into small elements and each connection point (node) is calculated by numerical analysis (Arbaoui, Tarfaoui and Malki, 2015). In this way, the parameters needed are: the initial load generated to the specimen, the characteristics of the material, and the shape / size of the specimen. In this study, FEM analysis was carried out with the help of MSC Nastran software.

The purpose of this study is to obtain the stress distribution that occurs in fracture zones in specimens using numerical simulations, and to obtain the characteristics of polymer foam composite material (PFCM) due to high rate dynamic impact load.

\section{Research Method}

PEBF was obtained from a plantation company PT. Nusantara IV, Adolina, North Sumatra, Indonesia (Fig. 2). Polyester resins and catalysts purchased from PT. Justus Kimia Raya, Medan, Indonesia and Polyol chemicals and their catalysts were purchased from PT. Rosma Bana Utama, Medan, Indonesia. The sample composition used based on the research of Zulfikar et al (Zulfikar, Umroh and Siahaan, 2019) is: 20\% foam generator, $60 \%$ resin, $10 \%$ catalyst, and $10 \%$ PEBF, and the number of specimens tested is as many as 15 samples.

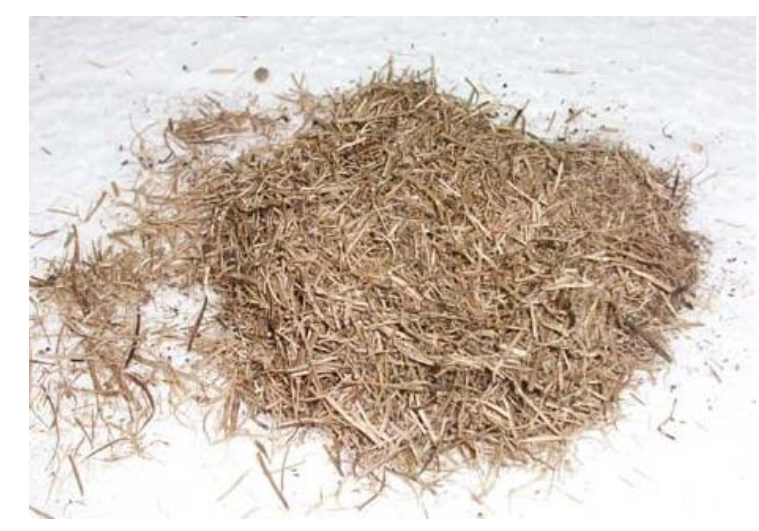

Figure 2. PEBF

Impact load dynamic testing uses an Air Gun Compressor (AGC) impact testing machine. This test tool is located at the Impact and Fracture Research Center (IFRC), Mechanical Engineering Department, Universitas Sumatera Utara, Indonesia (Fig. 3.a). This tool works with the principle developed by Kolsky. Fundamentally, the workings of this tool are that the strain wave propagation on this machine is generated by pressure in the compressor tank through 3 rod arrangements, namely the striker, input bar, and specimen (Fig. 3.b). In this study, testing used 4 bar air pressure, $200 \mathrm{~mm}$ striker length with impact distance variations of 100,300 and $500 \mathrm{~mm}, 2000 \mathrm{~mm}$ input bar length, and $200 \mathrm{~mm}$ specimen length. The specimen is placed right at the end of the input bar with a surface position that is dense with the surface of the input bar (Fig. 4). On the surface of the specimen are placed two strain gages with a distance of $100 \mathrm{~mm}$ which serves to read the strain waves that will propagate on the surface. 
Budapest International Research in Exact Sciences (BirEx) Journal Volume 2, No 1, January 2020, Page: 86-95 e-ISSN: 2655-7827 (Online), p-ISSN: 2655-7835 (Print) www.bircu-journal.com/index.php/birex emails: birex.journal@gmail.com birex.journal.qa@gmail.com

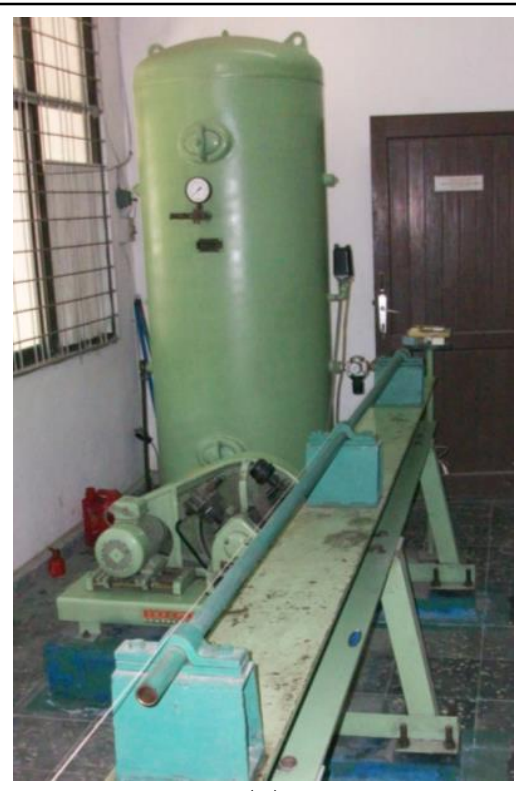

(a)

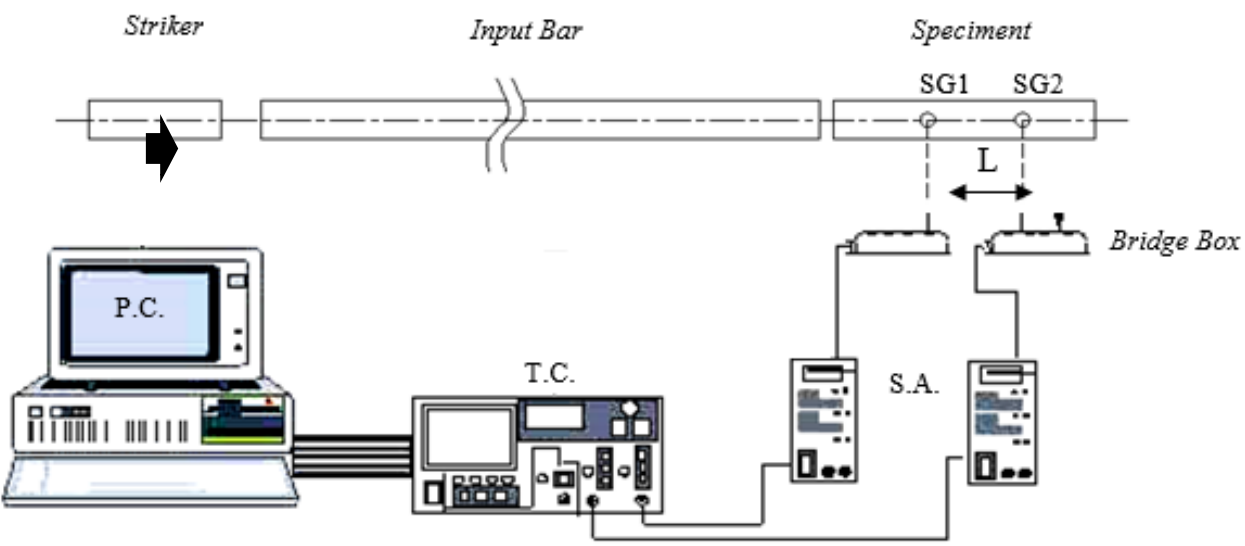

(b)

Figure 3. AGC type Impact test machine: (a) the arrangement; (b) data schematic

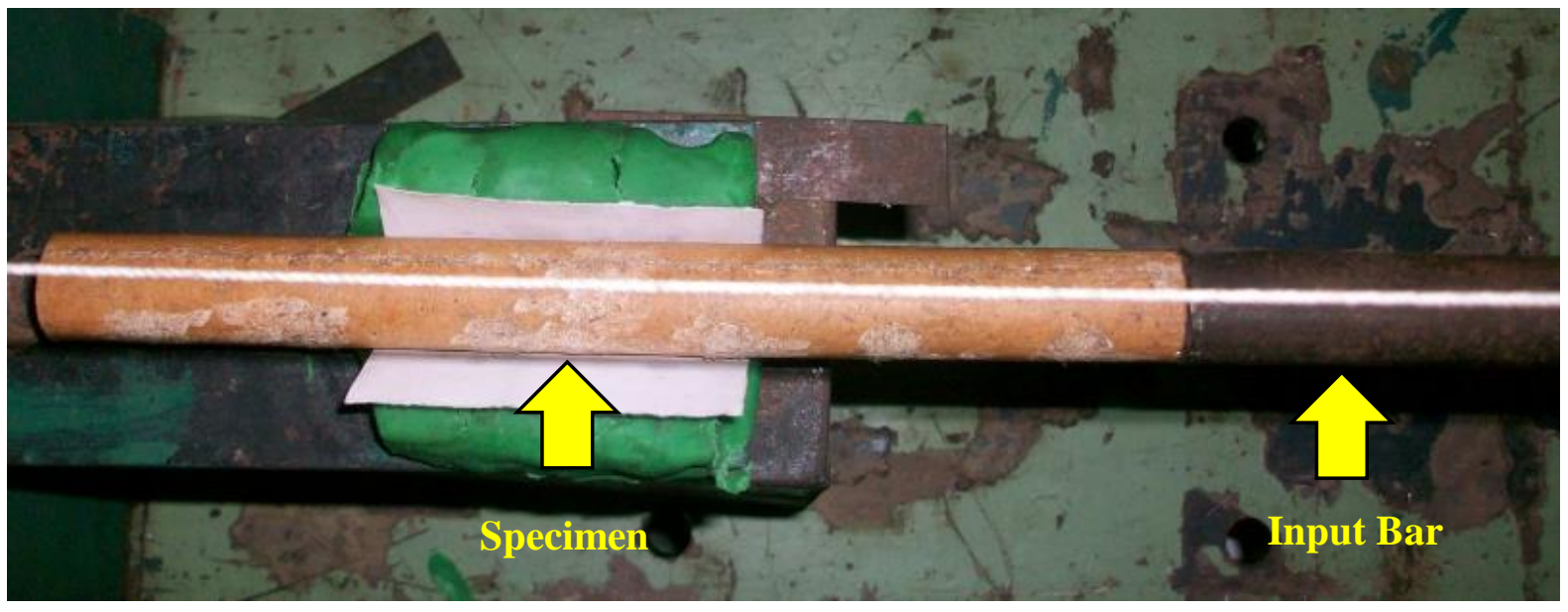

Figure 4. Position the specimen surface at the tip of the input bar 
Numerical analysis was performed using MSC Nastran software version 4.5. The shape of the specimen is assumed to be symmetrical so that the simulation can be done in two dimensions. The type of loading used is Dynamic Analysis with the Direct Transient method and the simulation time for each step is $0.4 \mathrm{~ms}$.

\section{Results}

Based on the test results, the specimen experiences a break at a distance between 150 and $170 \mathrm{~mm}$ from the end of the input bar at which the load is initially generated (Fig. 4.a). The material behaves as brittle material due to an impact dynamic load which is shown by the shape of the fracture that occurs (Fig. 5.b).

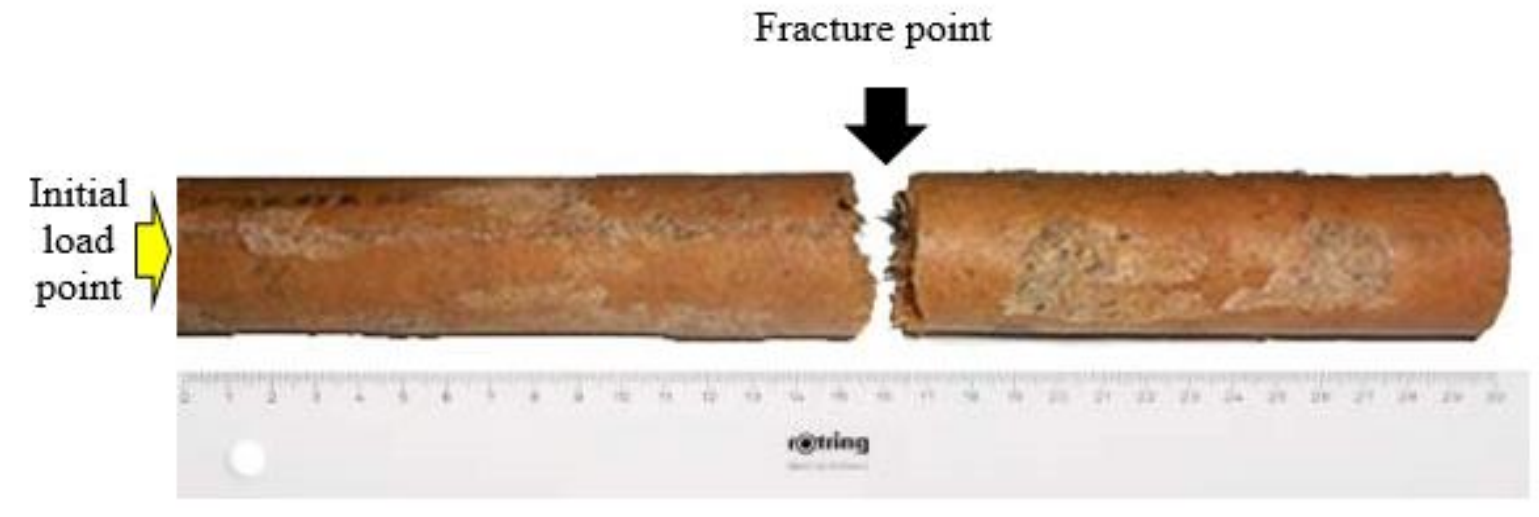

(a)

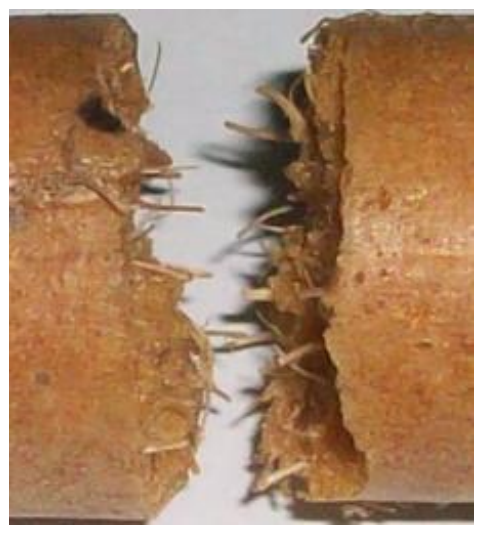

(b)

Figure 5. Impact specimen: (a) initial load and fracture point; (b) fracture shape

Based on experimental results, the failure of the specimen occurs at the time of propagation between $1900-2000 \mu \mathrm{s}(1.9-2.0 \mathrm{~ms})$, at which time the compressive stress (-) and tensile $(+)$ wave propagation intersect at a point in the specimen causing fracture in the specimen (Fig. 6). The distribution of stress data in the test of 15 samples ranged from 12-17 $\mathrm{MPa}$ with an average value of $13.8 \mathrm{MPa}$ (Fig. 7).

The amount of incident stress is obtained by using the pulse shaping model method. The magnitude of the value of incident stress is shown in Fig. 8 with an average value of 24.24 
MPa. By using equation (2), the initial impact load is $6873.87 \mathrm{~N}$. This load value will be used as initial load in numerical simulation.

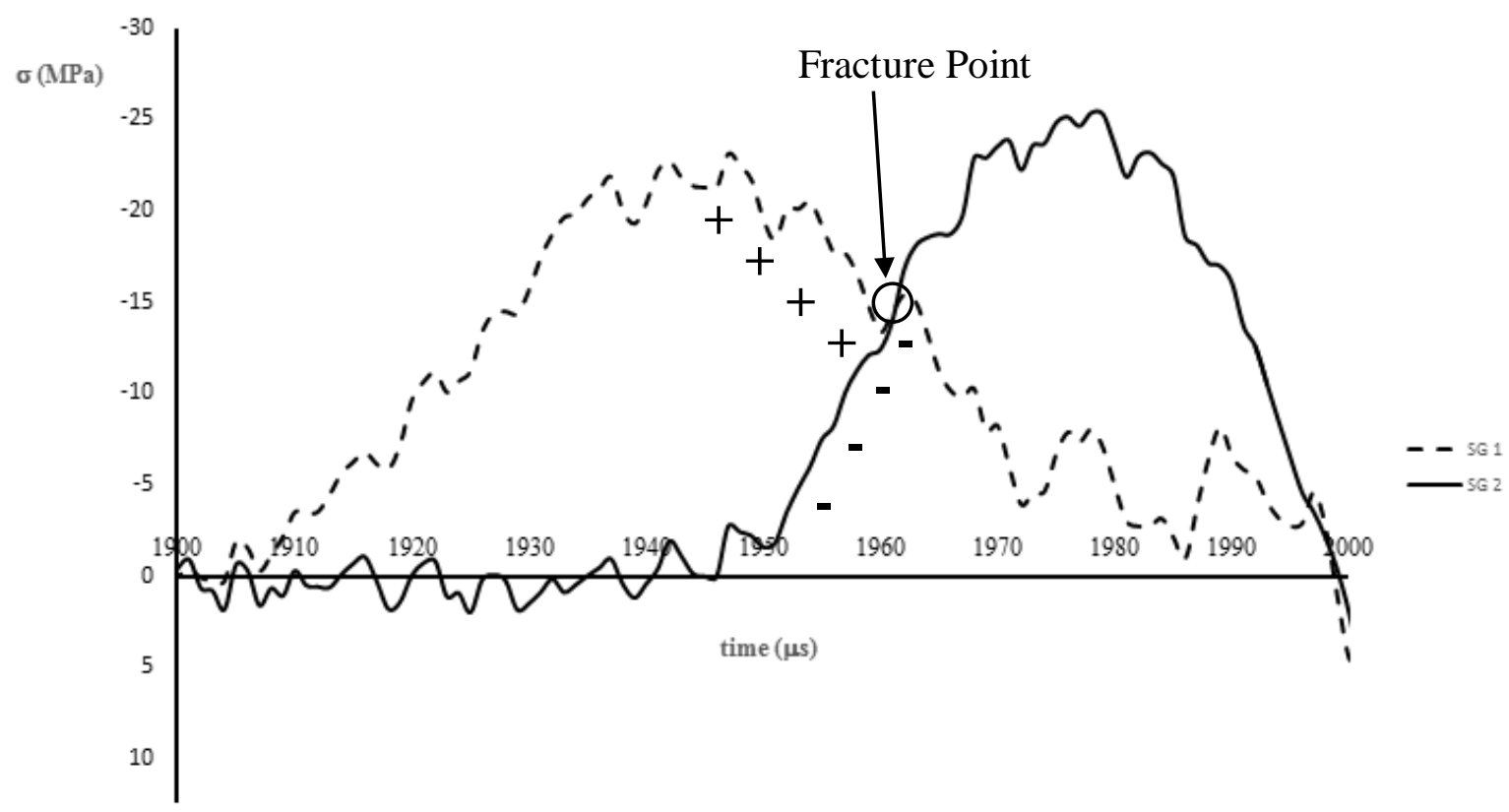

$S G 1=$ First strain gage $; S G 2=$ Second strain gage

Fig. 6. Chart of impact test result

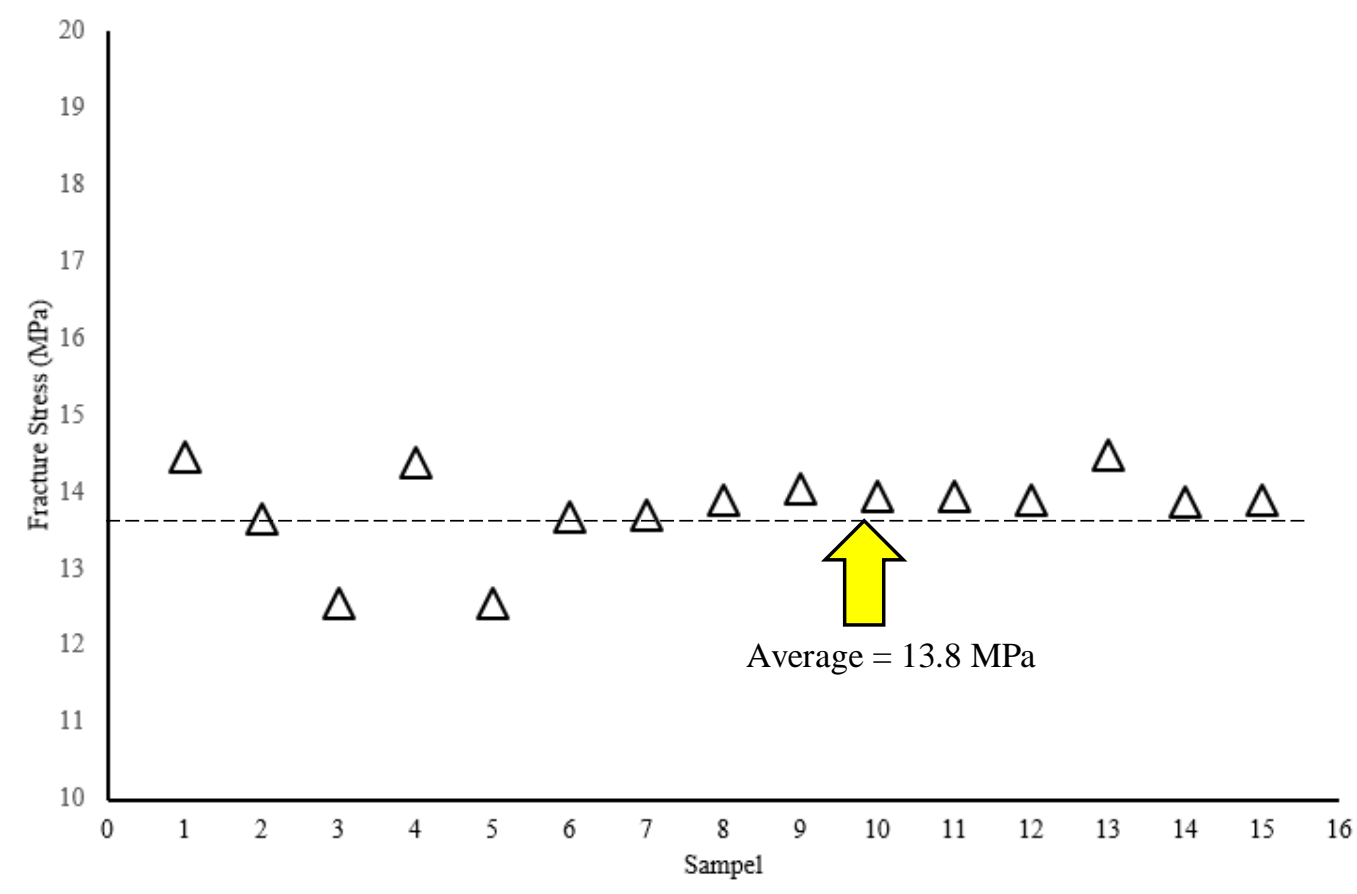

Figure 7. A collection of fracture stress values in testing of 15 samples 


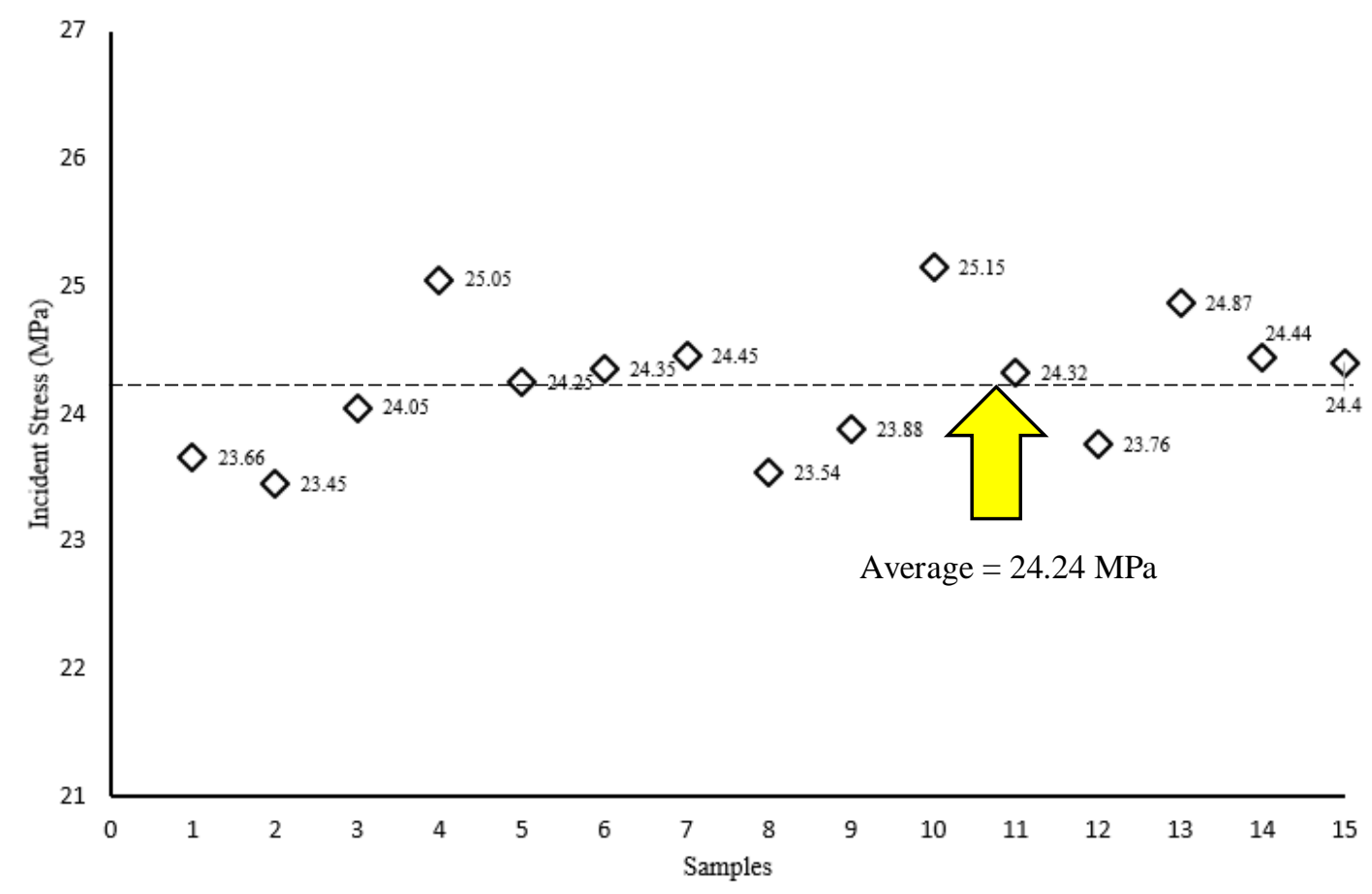

Figure 7. Incident stress values (average)

The setup of the MSC Nastran software is shown in Fig. 8. The type of analysis to be simulated is the type of Direct Transient with the duration of analysis at each step set to 300 $\mu \mathrm{s}$.

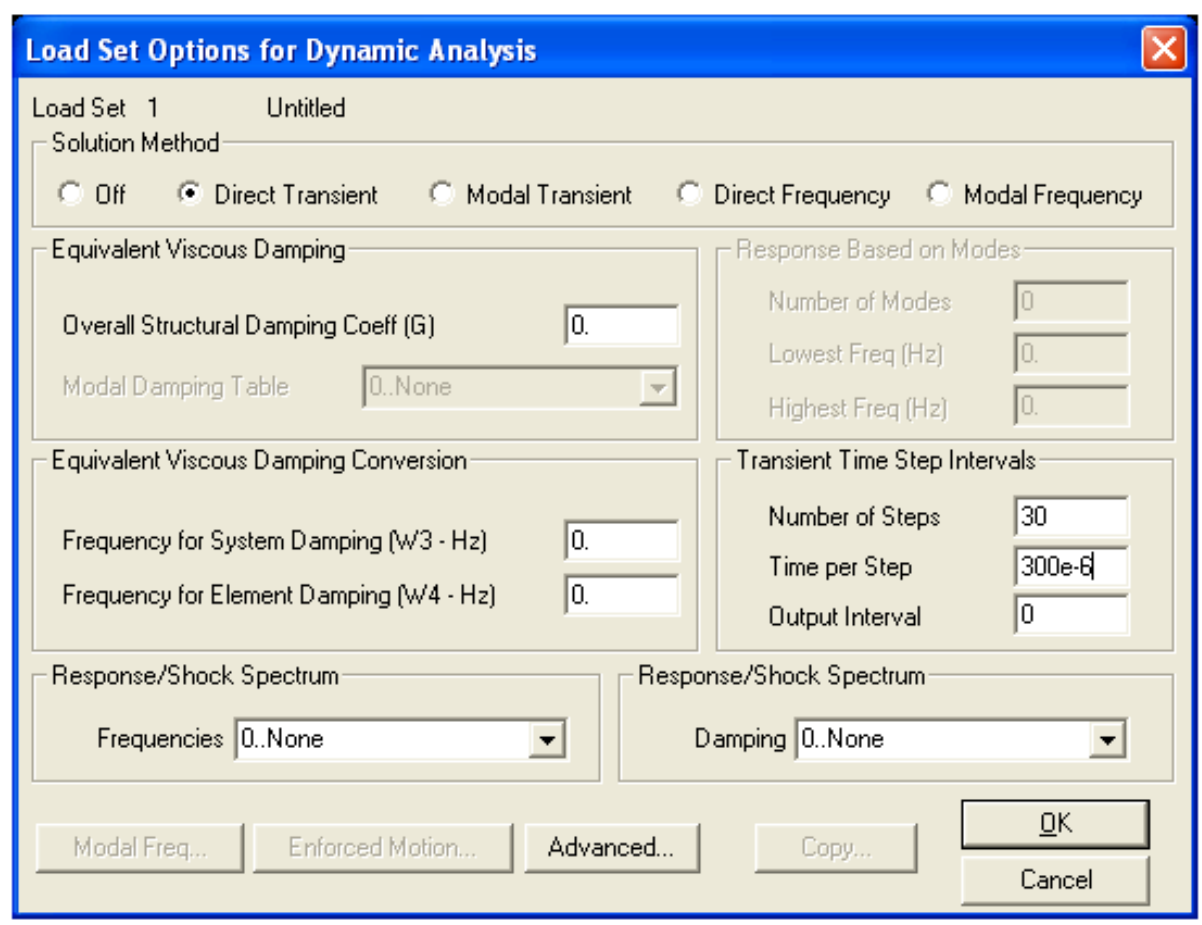

Figure 8. Setup of numerical analysis load for dynamic analysis in MSC Nastran

The results of numerical simulations are shown in Fig. 9. At $0.1 \mathrm{~ms}$, the compressive load propagates from the starting point of the load to the part that has not been subjected to a speed of around $80-100 \mathrm{~m} / \mathrm{s}$. At $0.9 \mathrm{~ms}$ after impacting, a second compressive load wave 
Budapest International Research in Exact Sciences (BirEx) Journal Volume 2, No 1, January 2020, Page: 86-95 e-ISSN: 2655-7827 (Online), p-ISSN: 2655-7835(Print) www.bircu-journal.com/index.php/birex emails: birex.journal@gmail.com birex.journal.qa@gmail.com

appears on the specimen in the same direction as the first compressive load. This wave appears as a result of the reflection wave of the striker to the input bar. At $1.7 \mathrm{~ms}$, the first load is reflected at the tip of the specimen and turns into a tensile load wave. Finally, at 2.1 ms the two types of strain waves meet and intersect with each other. In theory, the specimen will experience a fracture when two strain waves in different directions meet or intersect.

Stress wave propagation
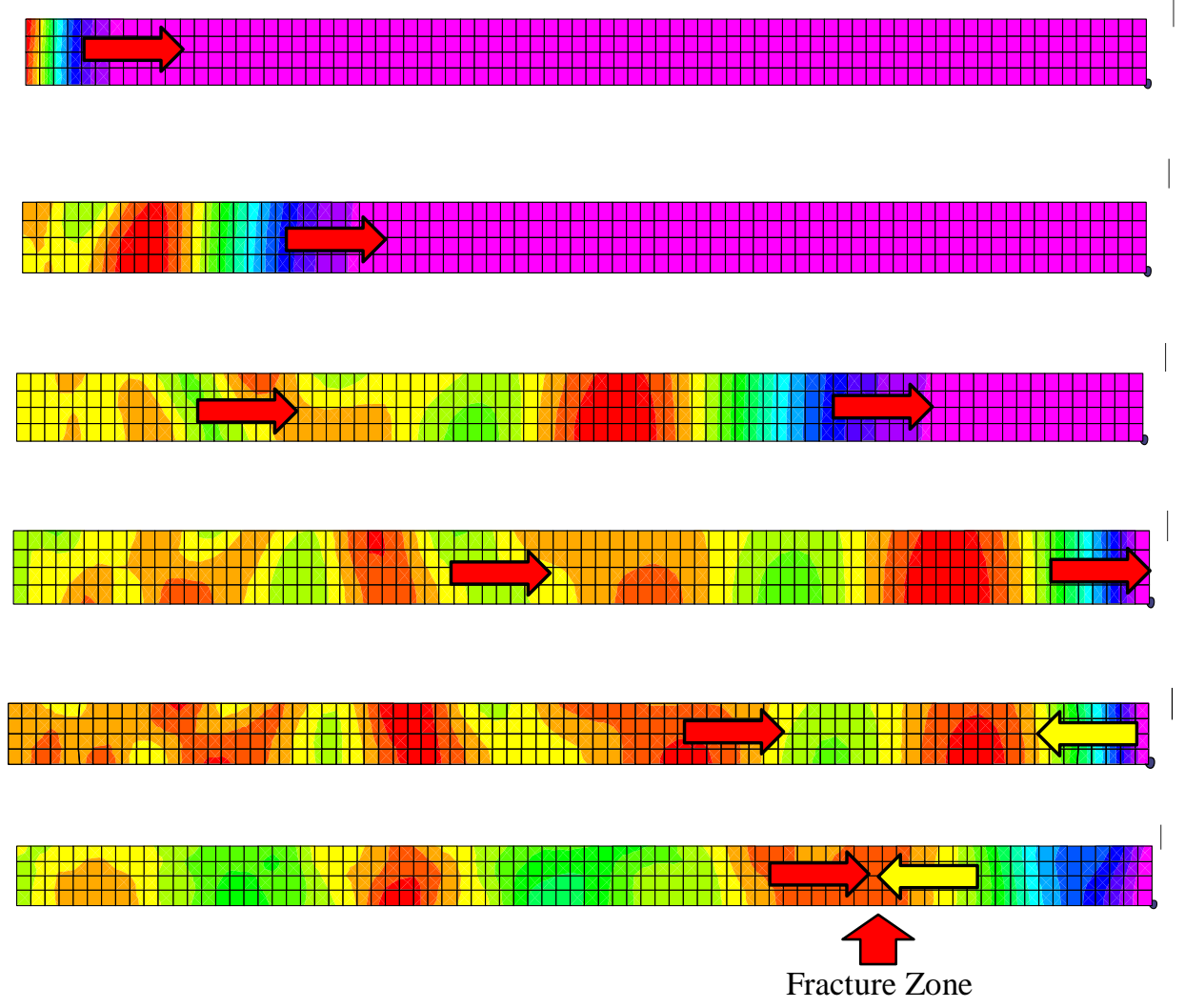

0.1

0.5

Time (ms)

= Compression stress/strain wave

Figure 9. Strain wave propagation in specimen due to high rate impact loading

The stress distribution in the fracture zone is shown in Fig. 10. (a) and (b). Based on numerical simulations, the stress that occurs in the fracture zone ranges from 17-19 $\mathrm{MPa}$, or greater about $28 \%$ of the results obtained experimentally. In numerical simulations, the load conditions are assumed to be ideal so that the influence of external factors such as temperature, air pressure, friction, gage factor, etc., is not involved. However, the simulation results can explain the high-speed strain wave propagation conditions that occur on the specimen surface.

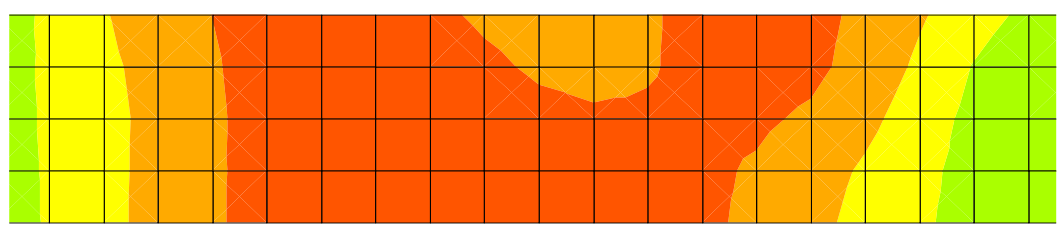

(a) 


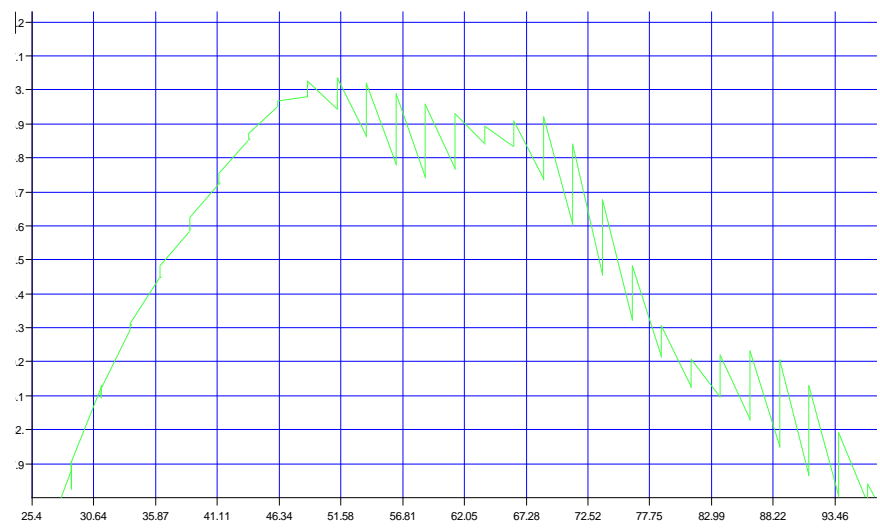

(b)

Figure 10. Stress distribution on fracture zone: (a) colored waveform contours; (b) stress graph

The pattern of strain/strain wave distribution on the surface of the specimen is like the pattern of ocean depth, where the darker color (red) is the area that experiences maximum load. The brighter the color of the contour that is shown indicates the smaller the load it is experiencing. In the fracture zone, two types of loads namely compress and tensile stress meet and intersect each other so that the fracture specimen with an average stress based on the simulation results is $18 \mathrm{MPa}$.

\section{Conclusion}

Based on the results of numerical simulations using MSC Nastran due to impact loads, especially in the fracture zone, the following conclusions are obtained: Based on the distribution of stresses that occur in the fracture region shows that two stresses in different directions intersect at high speed, which ranges from $80-100 \mathrm{~m} / \mathrm{s}$, at a point in the test specimen with a magnitude ranging from 17-19 MPa, and in very short time, which is about $2.1 \mathrm{~ms}$ or 0.0021 seconds after the first impact load enters the specimen surface. In addition there are also other strain waves that propagate on the specimen due to reflected waves at the tip of the specimen. Both of these stresses cause fracture on the test specimen. Based on the shape of the fracture, this material is classified as brittle material when this material experiences a high strain rate impact load. This is shown by the shape of the breakdown caused by the load (Fig. 5.b). The shape of the fracture showed that there was no hardening strain when the high strain waves propagated in the specimen, so that the shape of the necking was also not seen in the fracture results of the test specimen. Therefore, it is necessary to further develop this material so that it can be used for high impact load conditions and heavy work.

\section{Acknowledgments}

Thank you to the Program Studi Teknik Mesin, Faculty of Engineering,Universitas Medan Area for providing support and facilities in completing the report of this research. 
Budapest International Research in Exact Sciences (BirEx) Journal

Volume 2, No 1, January 2020, Page: 86-95

e-ISSN: 2655-7827 (Online), p-ISSN: 2655-7835(Print)

www.bircu-journal.com/index.php/birex

emails: birex.journal@gmail.com

birex.journal.qa@gmail.com

\section{References}

Arbaoui, J., Tarfaoui, M. and Malki, A. E. L. (2015) 'Mechanical behavior and damage kinetics of woven E-glass/Vinylester laminate composites under high strain rate dynamic compressive loading: Experimental and numerical investigation', International Journal of Impact Engineering. Elsevier Ltd. doi: 10.1016/j.ijimpeng.2015.06.026.

Azlina, N. et al. (2019) 'Tensile , physical and morphological properties of oil palm empty fruit bunch / sugarcane bagasse fibre reinforced phenolic hybrid composites', Integrative Medicine Research. The Authors, 8(4), pp. 3466-3474. doi: 10.1016/j.jmrt.2019.06.016.

Cavalcanti, P. P. and Tavares, L. M. (2019) 'Static and dynamic compressive loading of fi red iron ore pellets', Powder Technology, 354, pp. 281-288. doi: 10.1016/j.powtec.2019.06.006.

Chen, W. W. and Song, B. (2011) Split Hopkinson (Kolsky) Bar. Springer.

Elanchezhian, C. et al. (2018) 'Review on mechanical properties of natural fiber composites', Materials Today: Proceedings. Elsevier Ltd, 5(1), pp. 1785-1790. doi: 10.1016/j.matpr.2017.11.276.

Johan, M. et al. (2018) 'Environmental Technology \& Innovation Palm oil industry in South East Asia and the effluent treatment technology - A review sonvironmental Technology \& Innovation. Elsevier B.V., 9(May 2017), pp. 169-185. doi: 10.1016/j.eti.2017.11.003.

Sarpong-kumankomah, S., Gibson, M. A. and Gailer, J. (2018) 'Organ damage by toxic metals is critically determined by the bloodstream', Coordination Chemistry Reviews. Elsevier B.V., 374, pp. 376-386. doi: 10.1016/j.ccr.2018.07.007.

$\mathrm{Wu}, \mathrm{Y}$. et al. (2018) 'Development of natural fiber-reinforced composite with comparable mechanical properties and reduced energy consumption and environmental impacts for replacing automotive glass-fiber sheet molding compound', Journal of Cleaner Production. Elsevier B.V. doi: 10.1016/j.jclepro.2018.02.257.

Zulfikar, A. J., Umroh, B. and Siahaan, M. Y. R. (2019) 'Investigation of Mechanical Behavior of Polymeric Foam Materials Reinforced by Oil Palm Empty Fruit Bunches (OPEFB) Fibers Due to Static and Dynamic Loads', Journal of Mechanical Enggineering, Manufactures, Materials and Energy, 3(01), pp. 10-19. 